\title{
Kinetics of oxidative degradation of Rhodamine-B by $N$-bromosuccinimide in aqueous alkaline medium
}

\author{
Alaa Eldin Mokhtar Abdel-Hady \\ Department of Pharmaceutical Chemistry, Faculty of Pharmacy, Sinai University, Arish City, 45518, Cairo, Egypt \\ *Corresponding author at: Department of Pharmaceutical Chemistry, Faculty of Pharmacy, Sinai University, Arish City, 45518, Cairo, Egypt. \\ Tel.: +20.68.3336852; fax: +20.68.3336847. E-mail address: alaaeldin60@yahoo.com (A.E.M. Abdel-Hady).
}

\begin{tabular}{l} 
ARTICLE INFORMATION \\
Received: 11 April 2013 \\
Received in revised form: 01 May 2013 \\
Accepted: 15 June 2013 \\
Online: 31 December 2013 \\
KEYWORDS \\
\hline Kinetics \\
Oxidation \\
Rhodamine-B \\
$N$-Bromosuccinimide \\
Oxidative degradation \\
Inner-sphere mechanism \\
\hline
\end{tabular}

\section{Introduction}

Rhodamine-B is a basic organic dye, which contains four $\mathrm{N}$ ethyl groups at either side of the xanthene ring. It is widely used as a colorant in textile, leather, pharmaceutical, plastics, paint and food industries [1]. Over $15 \%$ of synthetic textile dyes used are lost during manufacturing or processing operations and released as effluents [2,3]. The effluent will produce adverse effects for soil and plants due to their non biodegradability, toxicity and potential carcinogenic nature $[3,4]$. For the treatment of dye containing wastewater, traditional physicochemical techniques such as adsorption on activated carbon, membrane separation and coagulation have difficulties in the complete destruction of dye pollutants [5]. Advanced oxidation technologies (AOTs) are attractive alternatives to nondestructive physical water treatment processes because they are able to mineralize organic contaminants. AOTs, such as Fenton reagent, photo-Fenton, $\mathrm{UV} / \mathrm{O}_{3}, \mathrm{UV} / \mathrm{H}_{2} \mathrm{O}_{2}$ and $\mathrm{TiO} 2^{-}$ mediated photocatalysis process based on the generation of reactive hydroxyl radicals $(\mathrm{OH} \cdot)$ have emerged to be promising alternatives for dye-off wastewaters [6-9]. Moreover, Rhodamine-B compounds, as a series of xanthene dyes have been widely used in analytical chemistry [10-12], especially in spectrometry $[13,14]$, fluorescence analysis $[15,16]$, catalytic and kinetic analysis [17]. In recent years, this series of compounds have been used as chemiluminescence (CL) reagents but $\mathrm{RhB}$ was considered as a sensitizer for the chemiluminescence system in most reports [18-22]. It was also used as a CL reagent in the determination of L-ascorbic acid [23] and DNA [24]. The chemiluminescence characteristics based on, oxidation of some xanthene dyes have been studied in alkaline aqueous solution [25-30]. The oxidation of $\mathrm{RhB}$ by $\mathrm{Ce}(\mathrm{IV})$ [31] was interpreted in the light of an inner-sphere mechanism through an intermediate complex formed by the two reactants. Succinimide and its derivatives are biologically and industrially useful compounds. Pharmaceutically, they are used as analgesics, nephrotoxic, anticonvulsant, and ionic inhibitors of human leukocyte. It has been reported that sulfonated derivatives of succinimide are more effective than aspirin and paracetamol. They are also used in industry as antifoaming agent, lubricating, emulsion explosive, and corrosion inhibitors. $\mathrm{N}$-bromosuccinimide serves as an oxidizing agent in the synthesis of drugs and hormones. Furthermore, NBS was used in oxidation, radical substitution and electrophilic addition reactions in organic chemistry. It was reported that the oxidation process proceeds via bromonium ion $\mathrm{Br}^{+}$[32] in polar medium or, alternatively through a free radical path involving the hemolytic dissociation of NBS with reducing metal ions yields useful intermediates. The initiation is considered to be effected by one of both succinimidyl and bromine free radicals $[33,34]$. Also, NBS can be considered as convenient source of cationic bromide.

In the present work, an organic dye pollutant, Rhodamine-B was chosen as the target pollutant to examine the rate of its oxidative degradation by NBS in alkaline medium and at different $\mathrm{MeOH}$-water solvent mixtures.

\section{Experimental}

\subsection{Chemicals and solutions}

Rhodamine-B chloride (Bakar, England) was obtained from Middle East Company of chemicals, Egypt. The working solutions were prepared by diluting a stock solution as needed. All reagent grade or Analar chemicals were used. Doubly distilled water was used in all kinetic runs and preparations. Freshly prepared solutions of NBS were prepared by accurate weighing. Buffer solutions were prepared using $\mathrm{NaOH}$ and Borax of known molarity. $\mathrm{NaCl}$ solution of known concentration 
was used to adjust the ionic strength in the different buffered solutions used.

\subsection{Kinetic procedure}

The reaction rates were monitored spectrophotometrically by measuring the decrease in the absorbance of $\mathrm{RhB}$ at $\lambda_{\max }=$ $554 \mathrm{~nm}$ with time on a Shimadzu PC 1700 UV-Vis. Spectrophotometer, (Figure 1). All the reactants, expect NBS were mixed and thermostated at the required temperature for 15-20 min. The required volume of separately thermostated NBS stock solution was thoroughly mixed and a sample was then transferred to an absorption cell. The $\mathrm{pH}$ of the reaction mixture was measured using 3505 Jenway pH-meter. Pseudofirst order conditions were maintained in all kinetic runs by using large excess concentrations of NBS (at least 10 fold) over $\mathrm{RhB}$ concentrations.

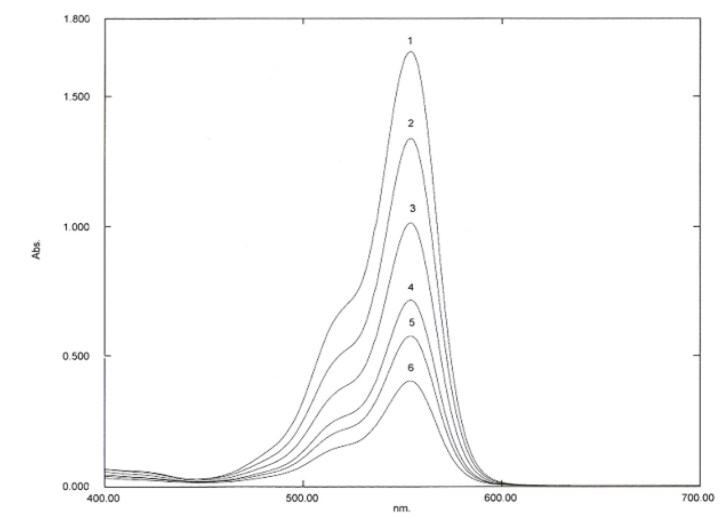

Figure 1. Change of the absorbance of Rhodamine-B with time. Peaks $1,2,3$, 4,5 , and 6 were measured at $0,3,5,10,15$, and $30 \mathrm{~min}$. from the time of initiation of reaction.

Oxidation of RhB by NBS was studied over 11.3-12.1 pH range, $0.1-0.5 \mathrm{~mol} / \mathrm{dm}^{3}$ ionic strength and $20-40{ }^{\circ} \mathrm{C}$ for a range of RhB and NBS concentrations. In order to verify the presence of the free radicals in the reaction, the following test was performed. A reaction mixture containing acrylonitrile was kept aside for 24 hours. On diluting the reaction mixture with methanol, since no precipitate was formed this suggests no possibility of free radical intervention in the reaction. When $\mathrm{AgNO}_{3}$ solution was added to the reaction mixture, pale yellow precipitate of $\mathrm{AgBr}$ was observed. Addition of succinimide (the reduced form of NBS) to the reaction mixture has no significant effect on the reaction rate.

\section{Results and discussion}

\subsection{Stoichiometry}

Experiments were carried out by varying the $[\mathrm{NBS}]:[\mathrm{RhB}]$ ratios, where the concentration of $\mathrm{RhB}$ was at least twice over that of [NBS] and the reaction mixtures were allowed to stand for $24 \mathrm{~h}$ until completion. The absorbance of the unreacted $\mathrm{RhB}$ ) was then measured and the concentration was calculated using its molar absorptivity. The results indicated that one mole of RhB consumed one mole of NBS and consistent with Scheme 1.

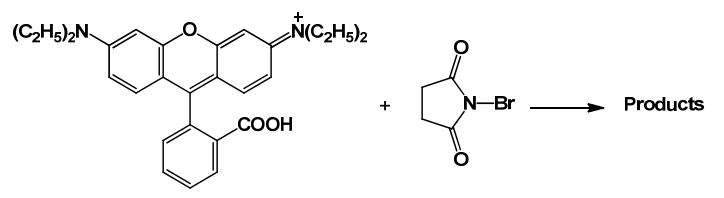

The rate of oxidation of RhB by NBS was measured at the commencement of the slow reaction at fixed [NBS], ionic strength, $\mathrm{pH}$ and temperature. Plots of $\ln \left(\mathrm{A}_{\infty}-\mathrm{A}_{\mathrm{t}}\right)$ and $1 /\left(\mathrm{A}_{\infty}-\mathrm{A}_{t}\right)$ versus time, where $A_{\infty}$ and $A_{t}$ are the absorbance at infinity and time $t$ respectively, showed marked deviations from linearity. The initial rate method was thus employed to calculate the rate of oxidation reaction. The initial oxidation rates $-\mathrm{d}[\mathrm{RhB}] / \mathrm{dt}$ at all $[\mathrm{RhB}]$ used were obtained from the slopes of the initial tangents of the absorbance versus time plots at $\lambda=554 \mathrm{~nm}$ employing the appropriate molar absorptivity of RhB at the $\mathrm{pH}$ 's used. The pseudo-first order rate constants, $\mathrm{k}_{\mathrm{obs}}$ were calculated by dividing the initial rates by the corresponding initial concentration of $\mathrm{RhB}$ used. Kinetics data (Table 1) showed that the values of $\mathrm{k}_{\mathrm{obs}}$ remain constant and were unaffected when the concentration of $\mathrm{RhB}$ was varied at constant [NBS], over the range 3.0-6.0 x $10^{-6} \mathrm{~mol}^{-\mathrm{dm}^{-3}}$ indicating that, the reaction was first order dependent on $[\mathrm{RhB}]$. Also, Plot of log initial rate $-\mathrm{d}[\mathrm{RhB}] / \mathrm{dt}$ versus log initial $[\mathrm{RhB}]$ was linear with slope $=1.0 \pm 0.15$. The reaction rate can therefore be represented by Equation (1).

$-\mathrm{d}[\mathrm{RhB}] / \mathrm{dt}=\mathrm{k}_{\mathrm{obs}}[\mathrm{RhB}]_{\mathrm{T}}$

where $[R h B]_{T}$, represents the total $[R h B]$ in the reaction mixture. $k_{o b s}$ is a composite value including the value the specific rate constant and the concentration of NBS. When the concentration of RhB increased above $1.0 \times 10^{-5} \mathrm{~mol} / \mathrm{dm}^{3}$, the rate of oxidation reaction found to decreases. This phenomenon may be attributed to the fact that, as the concentration of RhB increased, it started acting as a filter for the incident light, where its larger concentration will not permit the desired light intensity to reach the dye molecules in the bulk of the solution.

Table 1. Dependence of the reaction rate on $[\mathrm{RhB}],[\mathrm{NBS}]$ and temperatures at $\mathrm{pH}=11.3$ and $\mathrm{I}=0.1 \mathrm{~mol} . \mathrm{dm}^{-3}$.

\begin{tabular}{|c|c|c|c|c|}
\hline$\overline{\mathrm{T}\left({ }^{\circ} \mathrm{C}\right)}$ & $\begin{array}{l}10^{6} \times[\mathrm{RhB}] \\
\left(\mathrm{mol}^{\left.-\mathrm{dm}^{-3}\right)}\right.\end{array}$ & 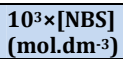 & 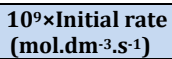 & $\begin{array}{l}10^{3} \times k_{\text {obs }} \\
\left(s^{-1}\right)\end{array}$ \\
\hline 20 & 3.00 & 1.00 & 4.08 & 1.36 \\
\hline 20 & 3.00 & 1.50 & 5.97 & 1.99 \\
\hline 20 & 3.00 & 2.00 & 7.95 & 2.65 \\
\hline 20 & 3.00 & 2.50 & 9.96 & 3.32 \\
\hline 20 & 3.00 & 3.00 & 12.03 & 4.01 \\
\hline 20 & 3.00 & 3.50 & 13.83 & 4.61 \\
\hline 20 & 3.00 & 4.00 & 15.84 & 5.28 \\
\hline 25 & 3.00 & 1.00 & 7.02 & 2.34 \\
\hline 25 & 3.00 & 2.00 & 16.27 & 4.65 \\
\hline 25 & 4.00 & 2.00 & 18.51 & 4.62 \\
\hline 25 & 5.00 & 2.00 & 23.05 & 4.61 \\
\hline 25 & 6.00 & 2.00 & 27.73 & 4.62 \\
\hline 25 & 3.00 & 3.00 & 20.79 & 6.93 \\
\hline 25 & 3.00 & 4.00 & 27.51 & 9.17 \\
\hline 30 & 3.00 & 1.00 & 11.82 & 3.94 \\
\hline 30 & 3.00 & 2.00 & 23.85 & 7.95 \\
\hline 30 & 3.00 & 3.00 & 35.91 & 11.97 \\
\hline 30 & 3.00 & 4.00 & 48.78 & 16.26 \\
\hline 35 & 3.00 & 1.00 & 16.05 & 5.35 \\
\hline 35 & 3.00 & 2.00 & 31.92 & 10.64 \\
\hline 35 & 3.00 & 3.00 & 47.88 & 15.96 \\
\hline 35 & 3.00 & 4.00 & 60.27 & 20.09 \\
\hline 40 & 3.00 & 1.00 & 22.89 & 7.63 \\
\hline 40 & 3.00 & 2.00 & 44.88 & 14.96 \\
\hline 40 & 3.00 & 3.00 & 65.04 & 21.68 \\
\hline 40 & 3.00 & 4.00 & 86.70 & 28.90 \\
\hline
\end{tabular}

Plots of $\mathrm{k}_{\mathrm{obs}}$ versus [NBS] at different temperatures over the range $20-40{ }^{\circ} \mathrm{C}$ as shown in (Figure 2) were linear with zero intercept with correlation coefficients, $r_{20}=0.99988, r_{25}=$ $0.99998, \mathrm{r}_{30}=0.99986, \mathrm{r}_{35}=0.99833$, and $\mathrm{r}_{40}=0.99987$. Thus, the dependence of $\mathrm{k}_{\mathrm{obs}}$ on [NBS] at different temperatures can be represented by Equation (2).

$\mathrm{k}_{\mathrm{obs}}=\mathrm{k}_{2}[\mathrm{NBS}]$ 


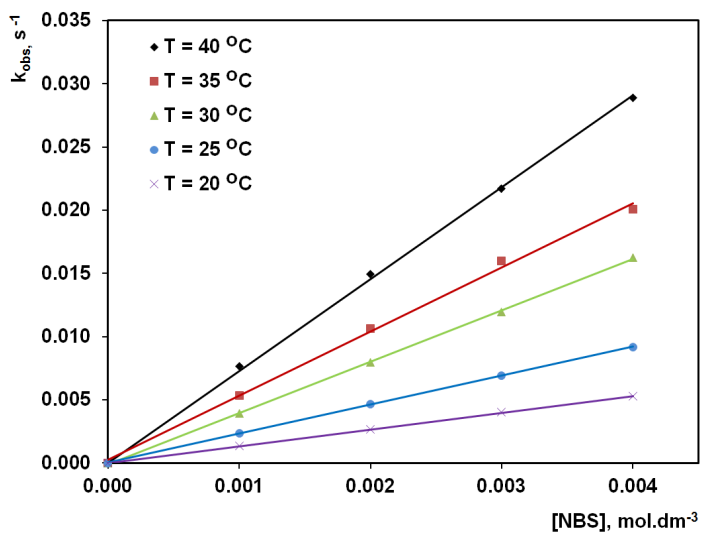

Figure 2. Plots of [NBS] versus $\mathrm{k}_{\mathrm{obs}}$ at different temperatures.

Values of $\mathrm{k}_{2}$ were calculated at different temperatures from the slopes of the plots (Table 2). Thermodynamic activation parameters including the enthalpy $\Delta H^{\ddagger}$ and entropy $\Delta S^{\ddagger}$ associated with $\mathrm{k}_{2}$ were calculated using a least square fit to the transition state theory equation as $59.7 \mathrm{~kJ} / \mathrm{mol}$ and -38.3 J/K.mol, respectively. The electron transfer step is an endothermic as indicated from the positive value of $\Delta H^{\ddagger}$. The composite negative $\Delta S^{\ddagger}$ value was claimed to be largely the result of substantial mutual ordering of solvated water molecules of the equilibrium and the intramolecular electrontransfer steps [35].The effect of $\mathrm{pH}$ on the rate of oxidation was studied by varying the $\mathrm{pH}$ values over the range 11.3-12.1 and keeping other parameters constant. Kinetics data (Table 3) showed that, the rate of oxidation reaction was decreased with increasing $\mathrm{pH}$ over the range studied and supported the involvement of the protonated form of Rhodamine-B, $\left(\mathrm{RhBH}^{+}\right)$ in the rate determining step. Plots of $\mathrm{k}_{\mathrm{obs}}$ versus [NBS] at different $\mathrm{pH}$ 's were linear with zero intercept with correlation coefficients, $r=0.99986, r=0.99879, r=0.99978$, and $r=0.99706$ at pH's, 11.3, 11.5, 11.8 and 12.1 , respectively (Figure 3). The dependence of $\mathrm{k}_{2}$ on $\mathrm{pH}$ is thus represented as,

$\mathrm{k}_{2}=\mathrm{k}_{3} /[\mathrm{OH}]^{-}$

Plot of $\mathrm{k}_{2}$ versus $\left[\mathrm{OH}^{-}\right]^{-1}$ according to (Table 4) was linear passing through the origin (Figure 4) and gave further confirmation to the Equation (3). Value of $\mathrm{k}_{3}$ was calculated from the slope of the plot as $0.01 \mathrm{~s}^{-1}$.

Table 2. Values of $\mathrm{k}_{2}$ at different temperatures.

\begin{tabular}{ll}
\hline $\mathbf{T}\left({ }^{\circ} \mathbf{C}\right)$ & $\mathbf{k}_{2}\left(\mathbf{m o l}^{-\mathbf{1}} \cdot \mathbf{d m}^{\mathbf{3}} \cdot \mathbf{s}^{-\mathbf{1}}\right)$ \\
\hline 20 & 1.33 \\
25 & 2.27 \\
30 & 4.09 \\
35 & 4.95 \\
40 & 7.05 \\
\hline
\end{tabular}

Table 3. Effect of $\mathrm{pH}$ on $\mathrm{k}_{\mathrm{obs}}\left(\mathrm{s}^{-1}\right)$ at $[\mathrm{RhB}]=3.0 \times 10^{-6} \mathrm{~mol} \cdot \mathrm{dm}^{-3}, \mathrm{I}=0.10$ mol.dm ${ }^{-3}$ and $\mathrm{T}=30^{\circ} \mathrm{C}$.

\begin{tabular}{lllll}
\hline $\mathbf{p H}$ & \multicolumn{4}{c}{$\mathbf{1 0}^{2} \times[\mathbf{N B S}]\left(\mathbf{m o l . d m}^{-3}\right)$} \\
\cline { 2 - 5 } & $\mathbf{4 . 0 0}$ & $\mathbf{3 . 0 0}$ & $\mathbf{2 . 0 0}$ \\
\cline { 2 - 5 } & & \multicolumn{3}{|c}{$\mathbf{1 0}^{3} \times \mathbf{k}_{\text {obs }}\left(\mathbf{s}^{-1}\right)$} \\
\hline 11.30 & 16.26 & 11.97 & 7.95 & 3.94 \\
11.50 & 12.31 & 8.71 & 5.91 & 2.74 \\
11.80 & 5.95 & 4.36 & 2.94 & 1.43 \\
12.10 & 3.09 & 2.23 & 1.55 & 0.93 \\
\hline
\end{tabular}

Table 4. Values of $\mathrm{k}_{2}$ at different $[\mathrm{OH}-]$.

\begin{tabular}{|c|c|c|c|c|}
\hline pH & $\begin{array}{l}\mathbf{k}_{2} \\
\left(\mathrm{~mol}^{-1} \cdot \mathrm{dm}^{3} \cdot \mathrm{s}^{-1}\right)\end{array}$ & pOH & 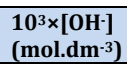 & $\begin{array}{l}{[\mathrm{OH}]^{-1}} \\
\left(\mathrm{~mol}^{-1} \cdot \mathrm{dm}^{3}\right)\end{array}$ \\
\hline 11.30 & 4.09 & 2.70 & 1.99 & 502.51 \\
\hline 11.50 & 3.15 & 2.50 & 3.16 & 316.45 \\
\hline 11.80 & 1.48 & 2.20 & 6.31 & 158.47 \\
\hline 12.10 & 0.72 & 1.90 & 12.50 & 80.00 \\
\hline
\end{tabular}

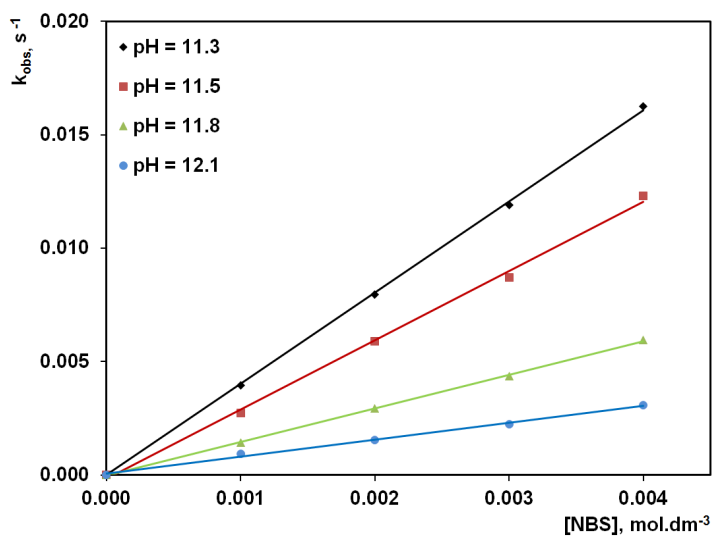

Figure 3. Plots of $\mathrm{k}_{\mathrm{obs}}$ versus [NBS] at different $\mathrm{pHs}$.

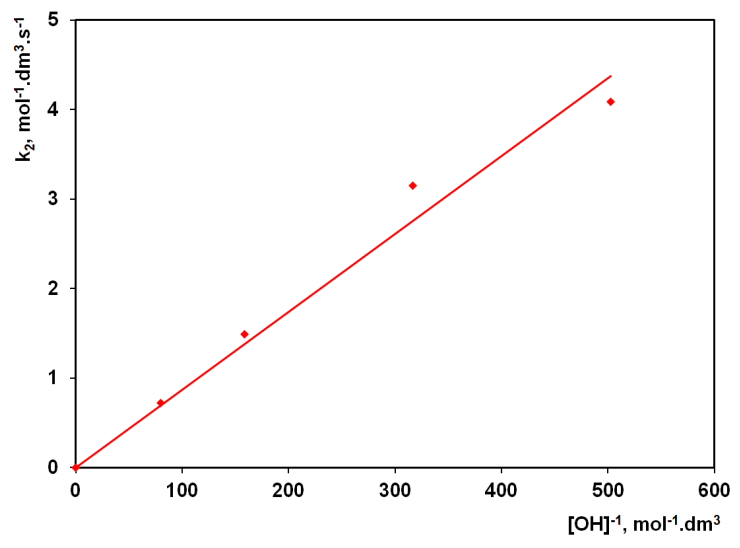

Figure 4. Plot of $\mathrm{k}_{2}$ versus $[\mathrm{OH}]^{-1}$. as,

From Equations (1), (2) and (3), the rate law is represented

$-\mathrm{d}[\mathrm{RhB}] / \mathrm{dt}=\mathrm{k}_{3}[\mathrm{RhB}][\mathrm{NBS}] /[\mathrm{OH}]^{-}$

In acidic and slightly basic media, the oxidation of RhB was very fast and the maximum absorbance of RhB at $554 \mathrm{~nm}$ declined quickly to the extent of disappearance and its blood red colour faded away instantaneously. The effect of ionic strength on the reaction rate was studied by varying the ionic strength of the medium using an aqueous solution of $\mathrm{NaCl}$ and maintaining other parameters at constant values. The experimental data (Table 5) indicated that, there is no significant effect of the ionic strength on the values of $\mathrm{k}_{\mathrm{obs}}$ and supported that; the reaction took place between charged and noncharged species. The effect of ionic strength on the reaction rate has been considered according to Bronsted and Bjerrum theory through the formation of an intermediate complex. The effect of dielectric constant (D) on the oxidation rate was investigated by using different $\mathrm{MeOH}$-water solvent mixtures over 0-30 wt \% methanol range at $\mathrm{T}=40{ }^{\circ} \mathrm{C}$, at constant $\mathrm{pH}$, ionic strength, [RhB], and [NBS]. Values of the dielectric constant for various weight percentage compositions of $\mathrm{MeOH}$ water solvent mixtures were abstracted as reported [36]. Values of $\mathrm{k}_{\text {obs }}$ (Table 6) indicated that the rate of oxidation decreased as the $\mathrm{MeOH} \%$ increased. Plot of Log $\mathrm{k}_{\text {obs }}$ versus 1/D was linear with negative slope (Figure 5). The kinetics data and graphical relations, in addition to the capability of NBS to coordinate the substrate through the carbonyl group [37] may support the following mechanistic pathway for the oxidation of RhB by NBS. 
Table 5. Effect of ionic strength on the reaction rate. $\mathrm{T}=30{ }^{\circ} \mathrm{C},[\mathrm{NBS}]=0.002$ mol.dm ${ }^{-3},[\mathrm{RhB}]=3 \times 10^{-6} \mathrm{~mol}_{\mathrm{dm}} \mathrm{dm}^{-3} \mathrm{pH}=11.30$.

\begin{tabular}{ll}
\hline $\mathbf{I}\left(\mathbf{m o l}_{\mathbf{d m}} \mathbf{- 3}\right)$ & $\mathbf{1 0}^{\mathbf{3}} \mathbf{\times} \mathbf{k}_{\mathbf{o b s}}\left(\mathbf{s}^{\mathbf{1}}\right)$ \\
\hline 0.10 & 7.95 \\
0.20 & 8.01 \\
0.30 & 7.88 \\
0.40 & 7.92 \\
\hline
\end{tabular}

Table 6. Effect of dielectric constant of the reaction medium on the $\mathrm{k}_{\mathrm{obs}}$.

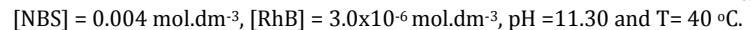

\begin{tabular}{lllll}
\hline MeOH (W\%) & D & 1/D & $\mathbf{1 0}^{3} \times \mathbf{k}_{\text {obs }}\left(\mathbf{s}^{-1}\right)$ & $\log \mathbf{K}_{\text {obs }}\left(\mathbf{s}^{\mathbf{1}}\right)$ \\
\hline 0 & 73.12 & 0.0136 & 28.90 & -1.54 \\
10 & 68.90 & 0.0145 & 9.87 & -2.01 \\
20 & 64.13 & 0.0156 & 2.07 & -2.68 \\
30 & 59.53 & 0.0168 & 0.73 & -3.13 \\
\hline
\end{tabular}

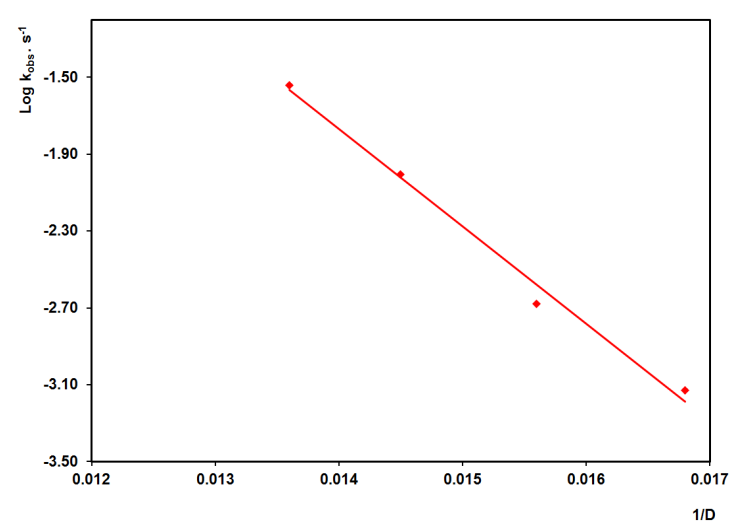

Figure 5. Plot of $\log \mathrm{k}_{\mathrm{obs}}$ versus 1/D.

$[\mathrm{RhB}]+\mathrm{H}_{2} \mathrm{O} \stackrel{\mathrm{K}_{1}}{\rightleftharpoons}[\mathrm{RhBH}]^{+}+[\mathrm{OH}]$

$[\mathrm{RhBH}]^{+}+[\mathrm{NBS}] \frac{\mathrm{k}_{4}}{\mathrm{k}_{-4}}[\mathrm{RhBH}(\mathrm{NBS})]^{+}$

$[\mathrm{RhB}]+[\mathrm{NBS}] \underset{\mathrm{k}_{5}}{\stackrel{\mathrm{k}_{5}}{\longrightarrow}}[\mathrm{RhB}(\mathrm{NBS})]$

$[\mathrm{RhBH}(\mathrm{NBS})]^{+} \stackrel{\mathrm{k}_{6}}{\longrightarrow}$ Products $+\mathrm{Br}^{-}+\mathrm{R}$.

$[\mathrm{RhB}(\mathrm{NBS})] \stackrel{\mathrm{k}_{7}}{\longrightarrow}$ Product $+\mathrm{Br}^{-}+\mathrm{R}$

where $K_{1}$, is protonation constant of $\mathrm{RhB}$ and $\mathrm{R}$, is the succinimidyl radical. The succinimidyl radical may prefer to abstract a hydrogen ion from the medium to form succinimide rather than dimerize to give bisuccinimidyl [38,39]. From the above mechanism and by using steady state approximation, the rate law is represented as,

$$
\begin{aligned}
& -\mathrm{d}[\mathrm{RhB}] / \mathrm{dt}=\mathrm{k}_{6}[\mathrm{RhBH}(\mathrm{NBS})]^{+}+\mathrm{k}_{7}[\mathrm{RhB}(\mathrm{NBS})] \\
& =\mathrm{k}_{6} \mathrm{k}_{4}[\mathrm{RhHB}]^{+}[\mathrm{NBS}] /\left(\mathrm{k}_{6}+\mathrm{k}_{-4}\right) \\
& \quad+\mathrm{k}_{5} \mathrm{k}_{7}[\mathrm{RhB}][\mathrm{NBS}] /\left(\mathrm{k}_{7}+\mathrm{k}_{-5}\right)
\end{aligned}
$$
(14).

Since, $\mathrm{k}_{6}>\mathrm{k}_{7}$, Equation (13) was reduced to Equation

$$
=[\mathrm{RhB}][\mathrm{NBS}]\left\{\mathrm{k}_{4} \mathrm{k}_{6} \mathrm{~K}_{1} /\left(\mathrm{k}_{6}+\mathrm{k}_{-4}\right)[\mathrm{OH}]^{-}\right\}
$$

and

$$
\begin{aligned}
& \mathrm{k}_{\mathrm{obs}}=[\mathrm{NBS}]\left\{\mathrm{k}_{4} \mathrm{k}_{6} \mathrm{~K}_{1} /\left(\mathrm{k}_{6}+\mathrm{k}_{-4}\right)[\mathrm{OH}]^{-}\right\} \\
& \text {Comparing Equation (2) and (15), then }
\end{aligned}
$$

$k_{2}=\left\{\mathrm{k}_{4} \mathrm{k}_{6} \mathrm{~K}_{1} /\left(\mathrm{k}_{6}+\mathrm{k}_{-4}\right)[\mathrm{OH}]^{-}\right\}$

and

$k_{3}=\left\{\mathrm{k}_{4} \mathrm{k}_{6} \mathrm{~K}_{1} /\left(\mathrm{k}_{6}+\mathrm{k}_{-4}\right)\right\}$

\section{Conclusion}

In this study, the kinetics of oxidative degradation of Rhodamine-B by $N$-bromosuccinimide into colourless degradation products was investigated. The rate of reaction was first order dependent on both [NBS], [RhB] and increased with decreasing $\mathrm{pH}$ over 11.30-12.10. The oxidative degradation of RhB by NBS may proceed via an inner-sphere mechanism through an intermediate complex, formed by the two reactants. On addition of acrylonitrile to the reaction mixture and dilution with $\mathrm{MeOH}$, no polymerization was observed, which indicated no free radical intervention.

\section{References}

[1]. Behnajady, M. A.; Modirshahla, N. Ing. Chem. Res. 2006, 45, 55535557.

[2]. Lee, J. W.; Choi, S. P.; Thiruvenkatachari, R.; Shim, W. G.; Moon, H. Dyes Pigments 2006, 69, 196-203.

[3]. Wang, S. Dyes Pigments 2008, 76, 714-720.

[4]. Ling, S. K.; Wan, S.; Peng, Y.J. Hazard. Mater. 2010, 178, 385-389.

[5]. Arslan-Alaton, I.; Ferry, J. L. Dyes Pigments 2002, 54, 25-36.

[6]. Alhamedi, F. H.; Rauf, M. A.; Ashraf, S. S. Desalination 2009, 238, 159166.

[7]. Yang, Z. He.; Ju,Y.; Sun, C. J. Env. Sci. 2009, 21, 268-272.

[8]. Chen, M.; Ma, W.; Lietal, J. Env. Sci.Tech. 2004, 38, 1569-1575.

[9]. Merouani, S.; Hamdaoui, O.; Saoudi, F.; Chiha, M.; Petrier, C. J. Hazard. Mater. 2010, 175, 593-599.

[10]. Hinckly, D. A.; Saybold, P. G.; Borris, D. P. Spectrochim. Acta A 1986, 42, 747-754.

[11]. Li, Y. Q.; Qian, F.; Huang, Z. X. Chin. Chem. Lett. 2000, 11, 613-614.

[12]. Mandal, K.; Pearson, T. D. L.; Demas, J. N. Anal. Chem. 1980, 52, 21842189.

[13]. Lu, M. Y.; Liu, S. P. J. Instrum. Anal. 2001, 20, 35-37.

[14]. Wu, S. Z.; Fang, W. H. Chin. J. Anal. Chem. 1995, 23, 1247-1251.

[15]. Haddad, P. R. Talanta 1977, 24, 1-13.

[16]. Li, J. G.; Wang, Y. R.; Tang, Y. L.; Wei, Y. Q. Chin. J. Anal. Chem. 1997, 25, 590-593.

[17]. Li, Z. B.; Wang, J. L.; Cao, Q. E.; Xu, Q. H.; Li, L. Anal. Lab. Chinese 1999 18, 10-14.

[18]. Bersis, D.; Vassiliou, E. Analyst 1966, 91, 499-505.

[19]. Al-Tamarh, S. A.; Townshend, A. Anal. Chem. Acta 1987, 202, 247-250.

[20]. Townshend, A.; Wheatley, R. A. Analyst 1998, 123, 267-272.

[21]. Townshend, A. Analyst 1998, 123, 1041-1046.

[22]. Lancaster, J. S.; Worsfold, P. J.; Lynes, A. Analyst 1989, 114, 16591661.

[23]. Ma, Y. J.; Zhou, M.; Jin, X. Y.; Zhang, B. Z.; Chen, H.; Guo, N. Y. Anal. Chem. Acta 2002, 464, 289-291.

[24]. Chen, H.; Zhou, M.; Jin, X. Y.; Song, Y. M.; Zhang, Z. Y. Z.; Ma, Y. J. Anal. Chem. Acta 2003, 478, 31-36.

[25]. Ramette, R. W.; Sandell, E. B. J. Am. Chem. Soc. 1956, 78, 4872-4878.

[26]. He, Z. K.; Ling, L. S.; CAI, R. X.; Zeng, Y. E. Acta Chem. Sinica 1998, 56, 472-477.

[27]. Zhang, X. R.; Baeyens, W. R. G.; Vanderweken, G.; Calokerinos, A. C.; Nakashima, K. Anal. Chem. Acta 1995, 303, 121-125.

[28]. Wang, L.; Zhu, C. Q.; Yang, G. Fenxi Huaxue 1995, 23, 83-85.

[29]. Nakagama, T.; Yamada, M.; Hobo, T. Analyst 1989, 114, 1275-1278.

[30]. Chen, G. N.; Duan, J. P.; Hu, Q. F. Anal. Chim. Acta 1 994, 292, 159-167.

[31]. Yongjun, Ma.; Xiaoyong, J.; Min, Z.; Ziyu, Z.; Xiulan, T.; Hui. C. Anal. Chem. Acta 2003, 489, 173-181.

[32]. Mathur, N. K.; Narang, C. K. The determination of organic compounds with $N$-bromosuccinimide, Academ. Press, New York, 1975. 
[33]. Musgran, S. B.; Pandy, L.; Singh, K. Monatsh Chem. 1980, 111, 11351142.

[34]. Singh, B.; Pandy, L.; Sharma, J.; Pandy, S. M. Tetrahedron 1982, 38, 169-172.

[35]. Weaver, M. J.; Yee, E. L. Inorg. Chem. 1980, 19, 1936-1945

[36]. Akerlof, G. J. Am. Chem. Soc. 1932, 54, 4125-4139.

[37]. Varaprasad, D. V. P. R.; Mahadevan, V. J. Macromol. Sci. Chem. A 1983, 19, 781-795.

[38]. Hedaya, E.; Hinman, R. L.; Kibler, L. M.; Theodoropulos, S. J. Chem. Soc. 1964, 86, 2727-2728.

[39]. Keonig, T.; Brewer, W. J. Chem. Soc. 1964, 86, 2728-2730. 